\title{
NEW METHOD FOR EVALUATING BRONCHOMOTOR AND BRONCHOSECRETORY ACTIVITIES: EFFECTS OF PROSTAGLANDINS AND ANTIGEN
}

\author{
Yoshikazu YAMATAKE and Saizo YANAURA \\ Department of Pharmacology, Hoshi College of Pharmacy, \\ Ebara, Shinagawa-ku, Tokyo 142, Japan
}

Accepted January 6, 1978

\begin{abstract}
We devised a new method for measuring responses of canine airway museulature, bronchosecretion and bronchial vasculature simultaneously, in situ, and investigated the effects of prostaglandins $\mathrm{F}_{2 \alpha}$ and $\mathrm{E}_{2}$ and antigen-antibody reaction by using this model. The right bronchial artery was perfused with blood at a constant flow under artificial respiration. Airway musculature response was measured as a change in ventilation overflow with a modification of the Konzett-Rössler method; the airway secretory activity was measured with our stopper method for secretion volume and with the glass plate method for viscosity. Close intraarterial injections of prostaglandin (PG) $\mathrm{F}_{2 k}, 0.01-10 \mu \mathrm{g}$, into the right bronchial artery produced bronchomuscular and vascular constrictions, while those of $\mathrm{PGE}_{2}, 0.01-3 \mu \mathrm{g}$, produced dilatation in a dose dependent manner. A close intraarterial injection of $1 \mathrm{mg}$ protein of ascaris suum antigen to dogs with positive skin reaction produced bronchoconstriction and vascular dilatation. Thirty min intraarterial infusions of $\mathrm{PGF}_{2 n}, 0.3-3 \% \mathrm{~g} / \mathrm{min}$, and ascaris antigen, 0.03-0.3 $\mathrm{mg}$ protein/min, resulted in a dose-dependent increase in the volume of airway secretions, while those of $\mathrm{PGE}_{2}, 0.1-1.0 \mu \mathrm{g} / \mathrm{min}$, did not alter the secretory activity. These findings indicate that prostaglandin $F_{2 \alpha}$ in relatively high doses increases both bronchomotor tone and bronchosecretory activity, as does antigen-antibody reaction with ascaris antigen, and that the present method is useful for evaluating effects of drugs on the respiratory tract.
\end{abstract}

Bronchi and bronchioles reccive blood supply through the bronchial arteries. The bronchial circulation is therefore mainly responsible for maintaining functions of the airways. An increase in respiratory resistance during bronchial asthma attack is ascribed to constrictions of bronchi and bronchioles, and hypersecretion of mucus evoked by asthma is also the result of responses of bronchi and bronchioles (that is, those of secretory glands and goblet cells). The anatony of bronchial circulation, however, makes for limitations in physiological and pharmacological studies. Hitherto, hemodynamics of bronchial circulation have been studied with the aortic sack method by Horisberger and Rodbard (1), and with the aortic tube method by DeKock et al. (2). These techniques are, however, rather complex and are necessarily accompanied by surgical trauma.

To our knowledge, asthmatic responses to antigen introduced into the bronchial arteries have not been reported; nor have the bronchosecretory activities of prostaglandins (PGs).

In the present study, we designed a new technique for allowing the direct application of drugs to the bronchial artery in the dog and for evaluating responses of bronchial musculature, vasculature and secretion, simultaneously with drug administrations. Using this 
method we investigated the effects of PGs and ascaris antigen given directly into the bronchial artery.

\section{MATERIALS AND METHODS}

Techinitue for perfusing bronchial artery

Male mongrel dogs weighing between 7 and $17 \mathrm{~kg}$ were anesthetized with sodium pentobarbital (30 $\mathrm{mg} / \mathrm{kg} \mathrm{i.v.)}$ or $a$-chloralose $(100 \mathrm{mg} / \mathrm{kg} \mathrm{i.v.).} \mathrm{The} \mathrm{animals} \mathrm{were} \mathrm{im-}$ mobilized with decamethonium bromide (initial dose $0.4 \mathrm{mg} / \mathrm{kg}$ i.v. and supplemental doses $0.2 \mathrm{mg} / \mathrm{kg}$ i.v. every hour), and ventilated artificially through an endotracheal stopper (described below) connected to a positive respiratory pump (Natsume, $\mathrm{KN}-50$ ) at a constant volume and a frequency of 20 breaths/min (Fig. 1A). The chest was opened at the right fourth intercostal space. After heparinization (initial dose 500 units $/ \mathrm{kg}$ i.v, and supplemental doses 250 units/kg i.v. every hour), the right bronchial artery originating from one of the right intercostal arteries was cannulated and perfused with the dog's own blood delivered from the right femoral artery, using a constant flow pump (Tokyo Rika Kikai, MP-201). The flow was adjusted at the beginning of each experiment so that the perfusion pressure was approximately equal to the systemic arterial blood pressure, and was kept constant throughout the experiment. The perfusion pressure was measured between the pump and the perfused artery via a pressure transducer (Nihon Kohden, MPU-0.5), and

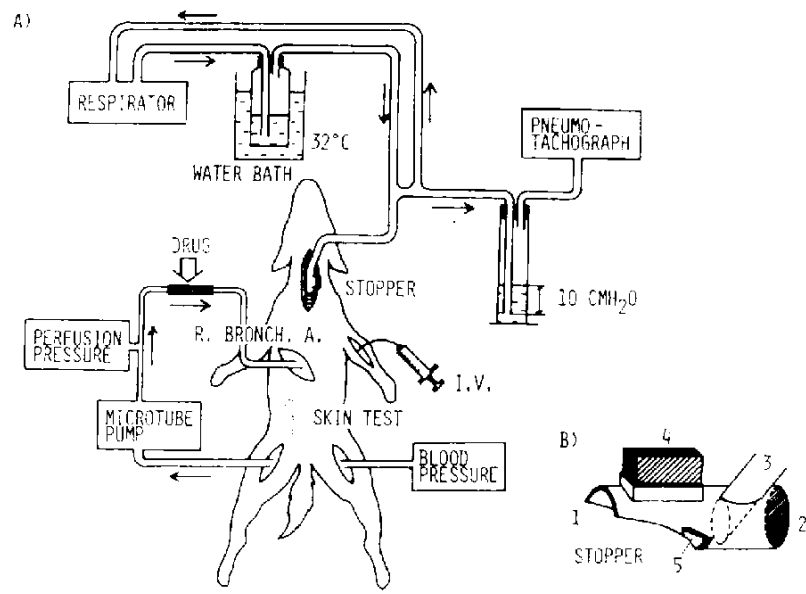

Fig. 1. A) Diagrammatic representation of the preparation for perfusing the right bronchial artery and for cvaluating airway responses in the dog. Details in text. B) Diagram of stopper. The stopper is made of a polyethylene tube cylinder $48 \mathrm{~mm}$ long, outer diameter $15 \mathrm{~mm}$, wall thickness $1 \mathrm{~mm}$. At the pulmonary end of stopper, 1, half of the circumference is cut away to introduce mucus into the stopper. The laryngeal end of stopper, 2, is completely closed. The air insufllated from an artificial respirator is introduced through a side arm of stopper, 3 , into the lungs. The plug of the stopper, 4 , is made of rubber, and is removed to collect the fluid accumulating in the stopper. A small plastic wall in the stopper. 5 , is provided in order that at one side, bronchosecretory fluid accumulates, and at the other side, water condensed, if any, along the vinyl tube connected with the respirator is accumulated without crossing over the boundary. 
TABLE 1. Area in lungs perfused by the right bronchial artery

\begin{tabular}{cccccc}
\hline $\begin{array}{c}\text { Right lung } \\
\text { Lobus } \\
\text { apicaris }\end{array}$ & $\begin{array}{l}\text { Lobus } \\
\text { cardiacus }\end{array}$ & $\begin{array}{l}\text { Lobus } \\
\text { diaphragmaticus }\end{array}$ & $\begin{array}{l}\text { Lobus } \\
\text { medius }\end{array}$ & $\mathrm{N}$ & $\%$ \\
\hdashline- & - & - & + & 54 & 84.4 \\
- & - & - & & 3 & 4.7 \\
& - & - & & 1 & 1.6 \\
- & & & 5 & 7.8 \\
& & & 1 & 1.6 \\
With a part of left lung & - & & 20.3 \\
With a part of alveoli & & & 14.1 \\
\hline
\end{tabular}

$\div$ : Significant blueing over the lobus by an i.a. injection of dye into the cannulated artery at the end of experiment. Note that in most cases the whole bronchi and bronchioles in the right lung were perfused.

was used as an index of the change in bronchial arterial resistance. The right bronchial artery was found to originate in an incidence of $62.5 \%$ from the 5 th, $32.1 \%$ from the 6 th, $1.8 \%$ from the 4 th and $3.6 \%$ from the $1 \mathrm{st}-3 \mathrm{rd}$ right bronchial artery, among 56 dogs. The systemic arterial blood pressure and heart rate were monitored from the cannulated left femoral artery via a pressure transducer and tachometer, respectively. These recordings were made on a polygraph (Nihon Kohden, RM-85). Close i.a. injections of drugs and antigen in volumes of $0.025 \mathrm{ml}$ and $0.17 \mathrm{ml}$, respectively, were given in $20 \mathrm{sec}$ into the perfused bronchial artery through the rubber tubing, in dogs anesthetized with pentobarbital or $\alpha$-chloralose. Close i.a. infusions of the agents were given in the same manner at the rate of $0.082 \mathrm{ml} / \mathrm{min}$ using an infusion pump (Natsume, $\mathrm{KN}$-202) in pentobarbital-anesthetized dogs. Perfused area in the lungs of the cannulated right bronchial artery was confirmed at the end of each experiment by injecting $1 \%$ pontamine sky blue solution in a volume of $5 \mathrm{ml}$ into the artery. The summary of the area perfused by the artery in 64 dogs is shown in Table 1. It was found that whole bronchi and bronchioles in the right lung and the right main bronchus were stained by the dye in most cases, while the left lung and alveoli in either lung were not substantially stained.

\section{Technique for measuring bronchomotor and bronchosecretory activities}

The bronchomotor tone was measured by a modification of the Konzett-Rössler method (3). To assess bronchosecretory activity we combined the method with our technique (the stopper method described below). The cervical trachca was exposed by a midline incision, and the surrounding connective tissue was carefully dissected from the cartilage. A midline incision was made at the 2 nd to 8 th cartilage rings beneath the cricoid cartilage and cauterization was used to minimize bleedings. A stopper, illustrated in Fig. 1B, was then inserted into the trachea. To insure tight positioning of the stopper, ligatures were placed at four points around the stopper-inserted portion of the trachea, taking care not to traumatize nerves or blood vessels. Insufflated air from the artificial respirator was warmed and humidified by passing through a water bath at $32^{\circ} \mathrm{C}$, and was introduced into the airways 
through the side arm of the stopper. The lung was inflated at a fixed volume of air under a constant pressure $\left(10 \mathrm{cmH}_{2} \mathrm{O}\right)$ and the ventilation overflow was measured with a differential flowmeter (Nihon Kohden, RFJ-5) as an index of the change in airway resistance. Tidal volume was adjusted at the beginning of each experiment so that the overflow was exactly $2.5 \mathrm{cc} / \mathrm{kg}$ body weight, and was kept constant throughout the experiment.

Bronchial secretion was measured only in the infusion experments. Just prior 10 drug infusion, tracheal mucosa in and adjacent to the endotracheal stopper was quickly cleaned with saline-moistened cotton after opening the plug of stopper. After the operation, the plug of the stopper was closed during infusion. Respiratory tract fluid which accumulated in the stopper for one hour including the first 30 min-period during drug infusion and the following 30 min-period after the end of drug infusion was collected with a spatula, and sucked up with a syringe of 0.25 or $0.5 \mathrm{cc}$ by opening the plug. The volume was measured with a syringe. Viscosity of the respiratory tract fluids collected was measured using the glass plate method (4). In brief, the device is as follows. A sample of secretion fluid in a volume of $0.04 \mathrm{ml}$ was placed on a glass plate $(6 \mathrm{~cm} \times 6 \mathrm{~cm})$ and then an inclined cover-glass $\left(4 \mathrm{~cm} \times 5 \mathrm{~cm}\right.$ ) weighing $0.23-0.25 \mathrm{~g}$ was allowed to fall from an angle of $5^{\circ}$ onto the plate. The extending area of the fluid on the plate 1 min after placing this cover-glass was measurcd as an index of the viscosity of the fluid. The percent concentration of aqueous dilution solution of a paste (Yamato No. 13; as a standard viscous fluid), the viscosity of which was equal to that of the test fluid, was expressed as the viscosity index of this particular fluid tested.

Drugs and antigen

The drugs used were prostaglandins $\mathrm{F}_{2 \kappa}$ (Prostarmon $\mathrm{F}$, Ono; $1 \mathrm{mg} / \mathrm{ml}$ phosphate buffer), $\mathrm{E}_{\mathrm{z}}$ (G512, Ono), histamine dihydrochloride (Wako Pure Chemicals) and isoproterenol hydrochloride (Sooner, Kaken Chemical). Solutions of $\mathrm{PGE}_{2}$ were prepared by dissolving the acid in phosphate buffer ( $\mathrm{pH} 7.4)(1 \mathrm{mg} / \mathrm{ml})$, kept frozen at $-20^{\circ} \mathrm{C}$, and the required rolume was made up with $0.9 \% \mathrm{NaCl}$ solution at the time of experiment. $\mathrm{PGF}_{2 \alpha}$, histamine and isoproterenol were dissolved or diluted with $0.9 \% \mathrm{NaCl}$ solution. Doses of histamine and isoproterenol were expressed in terms of the salt.

Ascaris suum antigen was prepared following the method previously described (5). Dogs naturally sensitive to ascaris antigen were selected by means of a skin test in which the animals that showed significant blueings at concentrations of below $10^{-\mathfrak{b}} \mathrm{g}$ protein $\mathrm{ml}$ of the antigen solution were estimated to be positive. Ascaris antigen was injected or infused i.a. to dogs with a positive skin reaction.

\section{RESULTS}

Basal values of main parameters under resting conditions

With the dogs under pentobarbital anesthesia, the average normal perfused blood flow: rate and tidal volume were $5.5 \pm 0.3$ (S.E.M.) $\mathrm{ml} / \mathrm{min}$ and $25 \div 1 \mathrm{cc} / \mathrm{kg}(\mathrm{N}=49)$, respectively. The corresponding values under anesthesia with $\alpha$-chloralose were $4.5 .50 .7 \mathrm{ml} / \mathrm{min}$ and $24 \pm 2 \mathrm{cc} / \mathrm{kg}(\mathrm{N}=15)$, respectively. The mean systemic arterial blood pressures were $135 \pm 3$ 
$(\mathrm{N}=49)$ and $130 \pm 3 \mathrm{mmHg}(\mathrm{N}=15)$, and the retrograde blood pressures of the right bronchial artery measured after cannulation were $62+5$ and $64 \pm 10 \mathrm{mmHg}$ under respective anesthesia. The preparation remained in good condition for $5 \mathrm{hr}$ or longer.

\section{Bronchomotor and bronchial rascular responses to i.a. drug injections}

Typical recordings of the changes in perfusion pressure, ventilation overflow, sysiamic blood pressure and heart rate produced by close i.a. injections of saline, histamine. isoproterenol, veronal buffered saline (VBS, the vehicle for ascaris antigen; an injection volume being $0.17 \mathrm{ml}$ equal to that of the antigen) and ascaris antigen in an experiment under pentobarbital anesthesia are shown in Fig. 2. Physiological saline did not produce any significant change in the parameters measured. Histamine in a dose of $3 \mu g$ i.a. caused a marked and rapid increase in overflow, viz., bronchoconstriction and a decrease in perfusion pressure, viz., vasodilatation with no substantial change in systemic blood pressure and heart rate. The duration of overflow response to listamine was 3.5 $\pm 0.5 \mathrm{~min}(\mathrm{~N}=9)$. Isoproterenol in a dose of 3, , g i.a. caused considerable decreases in overflow, viz., bronchodilatation and perfusion pressure in all instances (its duration being $5.5 \pm 0.7 \mathrm{~min}(\mathrm{~N}-7)$ ) accompanied

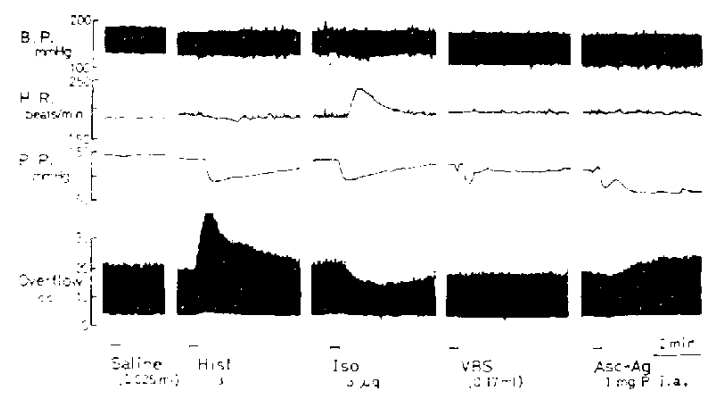

Fici. 2. Responses of the dog airway smooth muscles and bronchial yasculature to histamine, isoproterenol and ascaris antigen injected into the right bronchial artery . Tracings from top downward are the systemic arterial blood pressure (B.P.). heart rate (H.R.), perfusion pressure (P.P.; blood pressure of the right bronchial artery) and ventilation overflow. Histamine (Hisi) $3 \mu \mathrm{g}$, isoproterenol (Iso) 3 :"g, veronal-buffered saline (VBS), and ascaris sum antigen (Asc-Ag) $1 \mathrm{mg}$ protein, were injected at the bars below recordings.

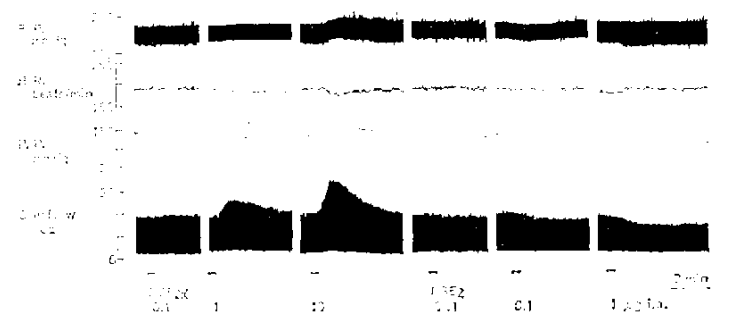

Fig. 3. Responses of the dog airway smooth muscles and bronchial vasculature to prostaglandins $F_{2 \alpha}$ and $E_{2}$ injected into the right brouchial artery. Tracings from top downward are the systemic arterial blood pressure (B.P.), heart rate (H.R.), perfusion pressure (P.P.; blood pressure of the right bronchial artery) and ventilation overflow. Drugs were injected at the bars below recordings. 
by a iachycardia. VBS in a volume of $0.17 \mathrm{ml}$ showed a decrease in perfusion pressure as was seen by an injection of an equal volume of saline.

Challenge by an i.a. injection of ascaris antigen in a dose of $1 \mathrm{mg}$ protein to dogs naturally sensitive to the antigen, induced an increase in ventilation overflow and a persistent fall in perfusion pressure in 4 out of the 8 dogs.

Typical recordings of the effects of i.a. injections of $\mathrm{PGF}_{2 \alpha}$ and $\mathrm{PGE}_{2}$ in a pentobarbitalized dog are shown in Fig. 3. The i.a. injections of 0.1 to $10 \mu \mathrm{g}$ of $\mathrm{PGF}_{2 a}$ resulted in a dose-iependent bronchoconstriction. Time required to attain the maximal response was

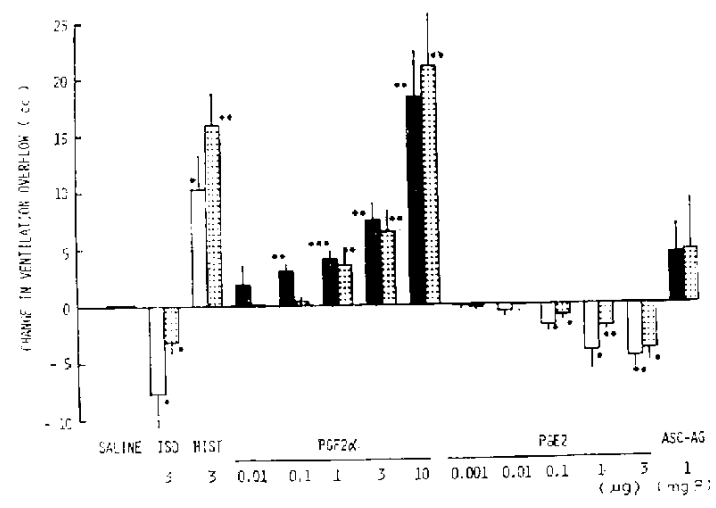

FIG. 4. Effects of isoproterenol, histamine, prostaglandins $\mathbf{F}_{2 \alpha}$ and $\mathrm{E}_{2}$, and ascaris suum antigen injected into the right bronchia! artery on the ventilation overflow in dogs. ISO: isoproterenol, HIST: histamine, and ASC-AG: ascaris antigen (mg protein). White and black columns show results obtained in pentobarbitalized clogs, and dotted columns are those in chloralosed dogs. Each column is the mean with S.E. for seven to nine animals. The changes are significant at *at $\mathrm{P}<0.05$.**at $\mathrm{P}<0.01$, and $* * *$ at $\mathrm{P}<0.001$.

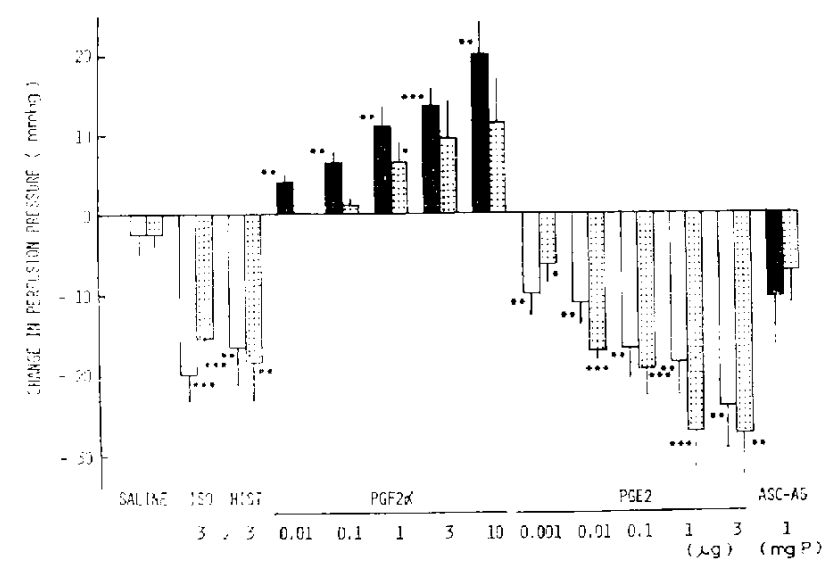

FIG. 5. Effects of isoproterenol, histamine, prostaglandins $F_{2 \alpha}$ and $E_{2}$, and ascaris suun antigen injected into the right bronchial artery on the perfusion pressure of bronchial vascular bed in dogs. 
Ionger with administration of $\mathrm{PGF}_{2 \varepsilon}$ than with that of histamine. The perfusion pressure was slightly increased by $\mathrm{PGF}_{2 \alpha}$ in most cases, whereas in one of the eight dogs it was decreased. $\mathrm{PGE}_{2}$ in doses of 0.01 to 1 /g i.a. caused a dose-dependent decrease in perfusion pressure and ventilation overflow. Mininal effects on mean systemic arterial blood pressure and heart rate were obtained up to $10 \mu \mathrm{g}$ for $\mathrm{PGF}_{2, x}$ and $1 / \mathrm{g}$ for PGE. Tachyphylaxis to the effects of both PGs was not apparent in the four animals tested. PGF $F_{2 \alpha}$ and PGE were administered by i.a. injections in a dose of 10 and $3 \mu \mathrm{g}$, respectively, for five successive times over a period of one hour with no diminution of bronchomotor effects.

The results of i.a. injections of the above drugs used on ventilation overflow and perfusion pressure are summarized in Figs. 4 and 5, respectively. More prominent bronchodilatations by isoproterenol and $\mathrm{PGE}_{2}$ were observed in the animals under pentobarbital anesthesia than under $\alpha$-chloralose anesthesia. The constriction of the bronchial musculature and vasculature caused by $\mathrm{PGE}_{2 x}$ was also more marked with the former anesthesia. The systemic conditions including blood pressure and heart rate were more stable under the former anesthesia. Thus, all the experiments to be described were carried out in animals anesthetized with pentobarbital. The threshold dose of $\mathrm{PGE}_{2}$ for vasodilatation was much lower than that for bronchodilatation. The bronchoconstrictory activity of PGF $F_{2 \alpha}$ seems to be lower than that of histamine, and the bronchodilatatory activity of $\mathrm{PGE}_{2}$ appears to be lower than that of isoproterenol.

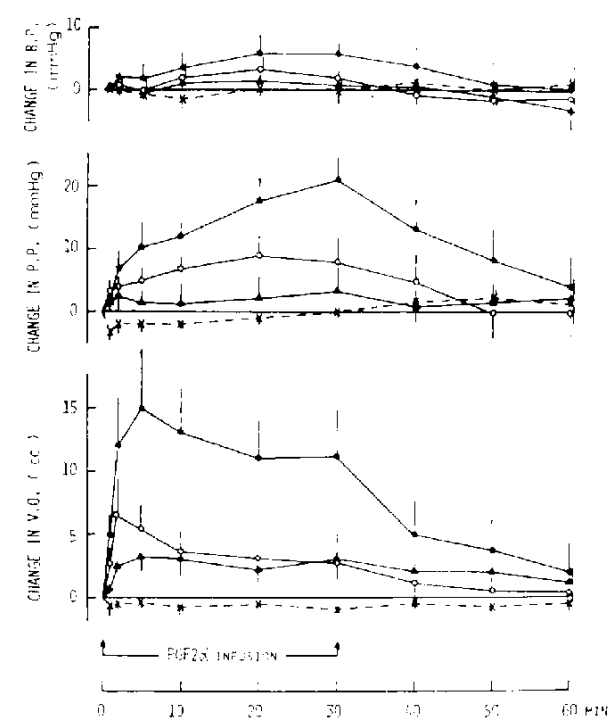

Fri. 6 . Effects of prostaglandin $\Gamma_{2 x}$ infused into the right bronchial artery on the ventilation overflow and bronchial vasculature in pentobarbitalized dogs. Response parameters from top downward are the changes in systemic arterial blood pressure (B.P.), perfusion pressure (P.P.; blood pressure of the right bronchial artery) and ventilation overflow (V.O.). The drug was infused during the first 30 min-period followed by a 30 min recovery period.

O: $\mathrm{PGF}_{2 \alpha} 3 \mathrm{zg}$ ! $\min$ i.a., $\bigcirc \quad \mathrm{PGF}_{2 \alpha} 1 \mathrm{~kg} / \mathrm{min}$ i.a., $\boldsymbol{\Delta} \Delta: \mathrm{PGF}_{2 \alpha} 0.3 \mu \mathrm{g} / \mathrm{min}$ i.a., $x \cdots \cdots \cdot$ : saline. 


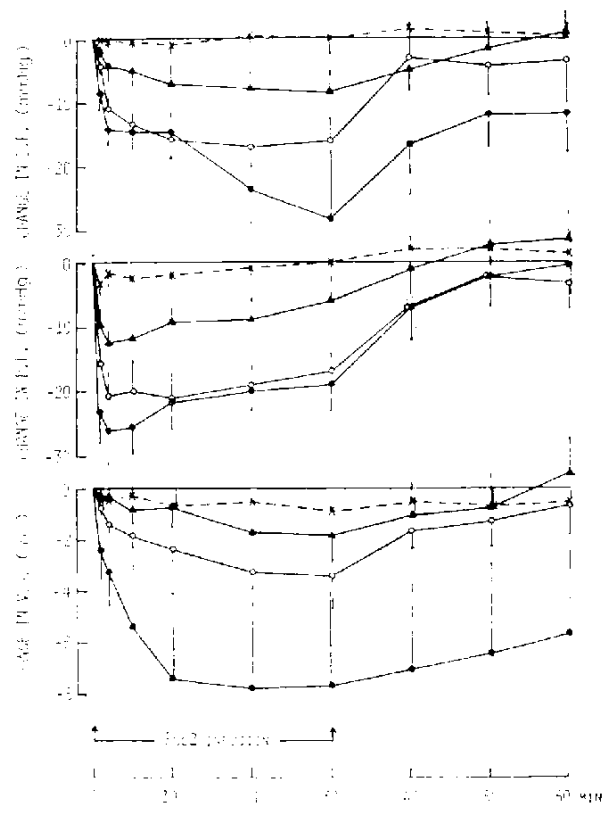

F1G. 7. Effects of prostaglandin $E_{2}$ infused into the right bronchial artery on the ventilation overflow and bronchial vasculature in pentobarbitalized dogs.

PGE $1 \mathrm{fg}$ min i.a., $O \quad \therefore \mathrm{PGE}_{2} 0.3$ :g/min i.a.,

A : $\mathrm{PGE}, 0.1, \mu \mathrm{g} / \mathrm{min}$ i.a., $\times \ldots . . ;$ saline. Other cxplanations as in Fig. 6.

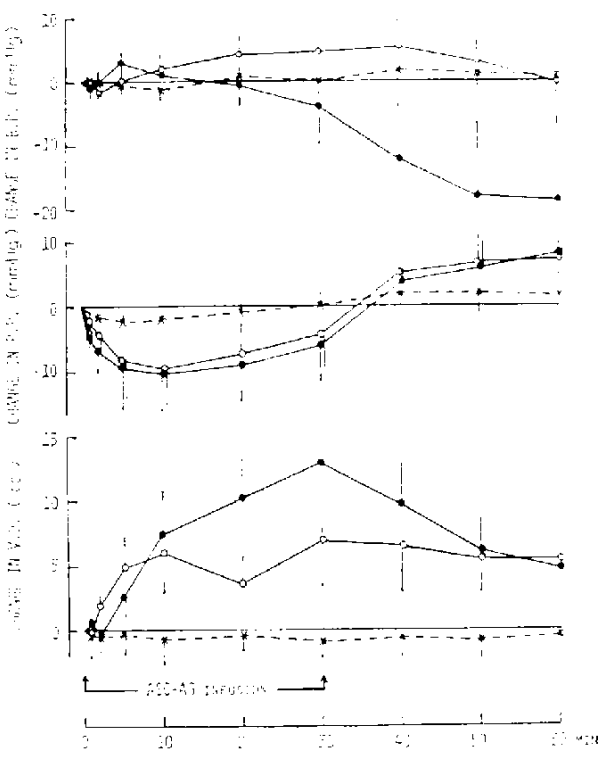

FiG. 8. Effects of ascaris anligen (ASC-AG) infused into the right bronchial artery on the ventilation overflow and bronchial vasculature in pentobarbitalized dogs. - O: ASC-AG $0.3 \mathrm{mg}$ protein min i.a., $\quad$ : ASC-AG $0.1 \mathrm{mg}$ protein min i.a., $x$... $x$ : saline. Oiher cyplanations as in Fig. 6.

Bronchomotor and bronchial lascular responses to i.a. drug infisions

The infusion experinents were carried out in pentobarbital-anesthetized dogs. Intusions of $\mathrm{PGF}_{2 \alpha}$ at 0.3 to 3 , gimin i.a., into the bronchial artery increased ventilation overllow and perfusion pressure dose-dependently, accompanied, in most animals, by a slight inerease in systemic blood pressure and tachycardia at higher doses (Fig. 6). The bronchoconstriction induced by an infusion of $\mathrm{PGF}_{2 \alpha}$ tended to lessen even during infusion. The response was recovered within about 30 min after cessation of the 30 min-infusion.

Infusions of $\mathrm{PGE}_{2}$ at 0.1 to $1, \mu \mathrm{g} / \mathrm{min}$ i.a., produced decreases in overflow and perfision pressure (Fig. 7). Associated with this was a systemic hypotension. The bronchodilatation

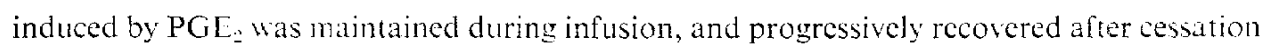
of infusion.

I.a. infusions of ascaris antigen at 0.1 to $0.3 \mathrm{mg}$ protein/min 10 dogs with positive skin reaction to the antigen, gave a rise in overflow and a fall in perfusion pressure after at $1.5-$ 4 min lag following the start of infusion (Fig. 8). These responses lasted during infusion in most cases, and were, in some cases, followed by a systemic hypotension, probably due to systemic anaphylaxis. 


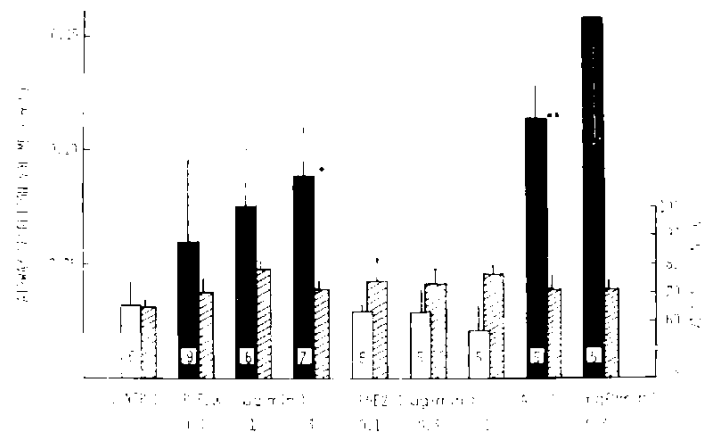

Fig. 9. Effects of prostaglandins $F_{2 a}$ and $E_{2}$, and ascaris antigen infused into the right bronchial artery on the airway secretion in pentobarbitalized dogs. Cont: saline infusion, ASC-AG: ascaris antigen infusion (mg protein/min). All drugs were infused for $30 \mathrm{~min}$. At $30 \mathrm{~min}$ after the end of infusion, airway secretions were collected and measured. White and black columns represent the secretion solume. Figures in the colomns indicate number of experiments. Hatched columns represent the viscosity of airway secretion. Vertical bars: the S.E. of means. Significant* at $\mathrm{P}<0.05$, and **at $\mathrm{P}<0.001$ vs. control.

\section{Bronchosecretory responses to i.a. drug infusions}

The results obtained are summarized in Fig. 9. The mean secretion volume for one hour after the start of i.a. infusion of saline was $0.032 \pm 0.010 \mathrm{ml}(\mathrm{N}=6)$. Infusions of $\mathrm{PGF}_{\mathrm{g}}$ in a dose range of $0.3-3 \mu \mathrm{g} / \mathrm{min}$ i.a. and those of ascaris antigen in doses of 0.1 and $0.3 \mathrm{mg}$ protein/min caused a dose-dependent increase in airway secretion volume, whereas infusions of $\mathrm{PGE}_{2}$ in a dose range of $0.1-1 \mu \mathrm{g} / \mathrm{min}$ had no effect on the airway secretion. There was no significant difference between the viscoclasticities of secretions collected after treatment with each drug.

\section{DISCUSSION}

Pertusion of the cranial thyroid arteries for measuring responses of dog tracheal musculature and vasculature, in situ, has been reported (6), but using this method, actions of drugs on the bronchi and bronchioles cannot be determined since only a part of the upper treachea is perfused. As a technique for drug administration into the bronchial arteries, Horisberger and Rodburd (1) devised the aortic sack method which consists of isolation of the aortic pouch from which the major bronchial arteries originate and of drug administration into this potich. The success ratio of operation is reportedly less than 50 percent as the animals do not tolerate well this surgery (7). DeKock et al. (2) inserted an aortic tube into the thoracic aorta and this method has drawbacks in that the operation and apparatus are complex and exact responses of the bronchial arteries and airways to drugs are not procurable since the drug given passes through most intercostal arteries as well as the bronchial arteries. Our present technique consists of a direct cannulation into the right bronchial artery and blood perfusion into the artery. The success ratio of surgery is substantially 100 percent. The right bronchial artery in most cases arises from one branch of one of the right intercostal arteries. Cannulation into the right bronchial artery makes feasible the perfusion of the 
bronchi and bronchioles in the entire right lung without perfusing alveoli. In a preliminary experiment, an injection of dye solution into the pulmonary artery stained most of the alveoli of both lungs, but not the bronchi and bronchioles. Prominent responses of respiratory tract could be observed when drugs were given into the cannulated right bronchial artery.

Using the present method, we assessed the bronchosecretory responses as well as responses of the bronchial vasculature and musculature, simultaneously. Among the methods for evaluating airway secretion in vivo, there is the direct method by Perry and Boyd (8), the dye leakage method by Sakuno (9), and the canine tracheal pouch method by Wardell et al. (10). Our stopper method is advantageous in that unlike the method of Perry and Boyd, measurement of secretory volume is not disturbed by evaporation or condensation of water in the tube through which humidified ventilatory air passes, and unlike the canine tracheal pouch method, the secretory activity throughout the airways, including bronchi and bronchioles, can be measured.

Using the aortic sack method (7) and the aortic tube method (2) the intrabronchial arterial injection of histamine induces a bronchoconstriction. With our preparation, a clear bronchodilatation after an i.a. administration of isoproterenol as well as a bronchoconstriction after histamine were observed. Thus our devised method makes feasible not only determination of bronchoconstricting responses but also bronchodilating ones.

Inhalation of ascaris sum antigen by dogs naturally sensitive to the antigen induces an asthmatic condition such as increases in respiratory resistance and secretion $(5,11)$. In the present study, it was confirmed that an i.a. administration of the antigen into the bronchial artery also induces a marked bronchoconstriction and an increase in bronchosecretory activity which are accompanied by a dilatation of the bronchial arterial bed. The bronchomotor response to an injection of the antigen, as compared with that to its infusion, was weak, or in some animals absent despite the appearance of systemic anaphylaxis, suggesting that in order to produce allergic reactions in the airways with an i.a. administration of the antigen, the tissues require sufficient exposure time to the antigen. The present study indicates that an i.a. infusion of ascaris antigen into the bronchial artery provides a useful model for inducing bronchial asthma, at least in laboratory animals.

It has been proposed that a defect in metabolism of one or more of the PGs and the ratio of $\mathrm{PGF}_{2: x}$ to $\mathrm{PGE}_{2}$ may be an underlying cause of bronchial asthma $(12,13)$. This speculation stems from the following findings; relatively high concentrations of PGs were found in the lungs in several animal species including humans (14), and in the plasma of asthmatic patients (15). PGs are released from guinea pig lung during acute antigenantibody reactions (16), and are detectable in the perfusate of antigen-treated, IgE-sensitized human lung tissue (17). A systemic intravenous injection or inhalation of $\mathrm{PGF}_{2 \alpha}$ is known to increase the bronchomotor tone, and $\mathrm{PGE}_{2}$ to decrease it in animals $(18,19)$, and humans $(20,21)$. There is apparently no report that PGs have been given directly into the bronchial arteries. Influence of PGs on bronchial secretions has also not been documented. The 
bronchoconstrictory effect of $\mathrm{PGF}_{2 \alpha}$ and bronchodilatory effect of $\mathrm{PGE}_{2}$ were confirmed herein by i.a. injections into the bronchial artery, the doses producing active responses of either drug bcing over $0.1 \mathrm{~kg}$. Pronounced bronchoconstrictory and bronchosecretory activities of $\mathrm{PGF}_{2 \alpha}$ were observed with i.a. infusion. Both the bronchomotor and secretory responses of $\mathrm{PGF}_{2, x}$ were similar to those seen in the cases of allergic reaction, while the vascular responses were opposite, that is, $\mathrm{PGF}_{2 a}$ showed vasoconstriction while a vasodilatation occurred with an allergic reaction. The doses of $\mathrm{PGF}_{2 \alpha}$ used in this experiment were considerably high as compared with concentrations of $P G F_{2 \alpha}$ in the lungs and bronchi of both humans and animals. Such are reportedly $12-50$ and $1.0-2.5 \mathrm{ng} / \mathrm{g}$, respectively

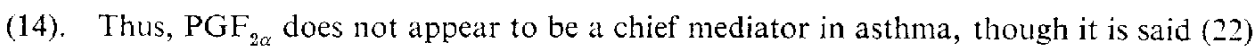
that effects of PGs may not depend upon the PGs stored in tissues, bur rather upon those produced in tissues when these tissues are stimulated by nerve excitation or some chenicals. The possibility that PGs may act as modulators of actions of other mediators such as histamine, is being investigated in our laboratory.

Acknowledgements: This work was supported in part by grant No. 277082 for scientific research from the Ministry of Education, Science and Culture, Japan. The assistance of Miss S. Sasagawa is also appreciated.

\section{REFERENCES}

1) Horisberger, B. And Rodbard, S.: Direct measurement of bronchial arterial flow. Circulation Res. 8, 1149-1156 (1960)

2) DeKock, M.A., Nadfe, J.A., Zwi, S., Colebatch, H.J.H. and Olsen, C.R.: New method for perfusing bronchial arteries-histamine bronchoconstriction and apnea. J. appl. Phy:siol. 21, 185-194 (1966)

3) KONZFTT, H. AND RöSSLER, R.: Versuchsanordnung zu Untersuchungen an der Bronchialmuskulatur. Arch. exp. Path. Phaimakol. 195, 71-74 (1940)

4) Yamatakl, Y., Sasagaha, S., Yanaura, S. and OkamiYa, Y.: Anti-allergic asthma effect of ipratropium bromide (Sch 1000) in dogs. Folia pharmacol. japon. 73, 785-791 (1977) (Abs. in English)

5) Yamatake, Y., Sasagawa, S., Yanalra, S. and Kobayashi, N.: Allergy induced asthma with ascaris sum administration to dogs. Japan. J. Pharmacol. 27, 285-293 (1977)

6) Himori, N. AND TAIRA, N.: A method for recording smooth muscle and vascular responses of the blood-perfused trachea in situ. Brit. J. Phaimacol. 56, 293-299 (1976)

7) DE Lirona, J.M.L., dL ia Mata, R.C. AND Avado, D.M.: Local and reflex effects of bronchial arterial injection of drugs. J. Pharmacol. exp. Ther. 133, 295-303 (1961)

8) Perry, W.F. ANd Boyd, E.M.: A method for studying expectorant action in animals by direct measurement of the output of respiratory tract fluids. J. Pharmacol. exp. Ther. 73, 65-77 (1941)

9) SAKU:io, E.: Pharmacological studies of expectorants, especially of the effect of autonomic nerve drugs on mucus secretions of the lower respiratory tract. $J$. Oriental Mrd. 33, 779-791 (1940) (in Japanese)

10) Wardeli, Jr., J.R., Chakrin, L.W. And Payti, B.J.: The canine tracheal pouch-A model for use in respiratory mucus researcl. Am. Rev. Resp. Dis. 101, 741-753 (1970)

11) GOLd, W.M., Kessler, G.-F. AND YU, D.Y.C.: Role of vagus nerves in experimental asthma in allergic dogs. J. appl. Physiol. 33, 719-725 (1972)

12) Parkfr, C.W. and Svider, D.E.: Prostaglandins and asthma. Ann. intern. Med. 78, 963-965 (1973)

13) Horton, E.W.: Hypotheses on physiological roles of prostaglandins. Physiol. Rev. 49, 1121$1161(1969)$ 
14) ANGGARD, E.: The isolation and determination of prostaglandins in lungs of sheep, guinea pig, monkey and man. Biochem. Pharmacol. 14, 1507-1516 (1965)

15. Green, K., Hedqvist, P. and Svanborg, N.: Increased plasma levels of 15-keto-13, 14dihydro-prostaglandin $F_{2}$ after allergen-provoked asthma in man. Lancet 2, 1419-1421 (1974)

16: PIPER, J.P. AND VANE, J.R.: Release of additional factors in anaphylaxis and its antagonism by anti-inflammatory drugs. Nature 223, 29-35 (1969)

17) PIPFR, J.P. AND WALKFR, J.L.: Release of spasmogenic substance from human chopped lung tissue and its inhibition. Brit. J. Pharmacol. 42, 291-304 (1973)

18) Rosmnitale, M.E., Dervinis, A. And Kassaricir, J.: Bronchodilator activity of prostaglandins $\mathrm{E}_{1}$ and $\mathrm{E}_{2}$. J. Pharmacol. exp. Ther. 178, 541-548 (1971)

19) Nakano, J., MCCloy, R.B. AND Prancan, A.V.: Circulatory and pulmonary airway responses to different mixtures of prostaglandin $F_{2}$ and $F_{: \alpha 6}$ in dogs. Europ. J. Pharmacol. 24, $61-66(1973)$

20) CUTHBERT, M.F.: Effect on airways resistance of prostaglandin $E_{1}$ given by aerosol to healthy and asthmatic volunteers. Brit. med. J. 4, 723-726 (1969)

21. Hedqvist, P., Holmgren, A. ANd Mathe, A.A.: Effect of prostaglandin $F_{2 c}$ on airway resistance in man. Acta physiol. scand. 82, 29A (1971)

22. Ferreira, S.H., Movcada, S. A.vo VANF, J.R.: Indomethacin and aspirin abolish prostaglandin release from the spleen. Nature 231, 237-239 (1971) 